\title{
Indirect load case estimation for propeller-ice moments from shaft line torque measurements
}

\author{
R.J.O. de Waal ${ }^{a}$, A. Bekker ${ }^{a}$, P.S. Heyns ${ }^{b}$ \\ a Sound and Vibration Research Group, Department of Mechanical \& Mechatronic Engineering, \\ Stellenbosch University, \\ Private Bag X1, Matieland 7602, South Africa \\ e-mail: annieb@sun.ac.za \\ ${ }^{b}$ The Centre for Asset Integrity Management, Department of Mechanical and Aeronautical Engineering, \\ University of Pretoria, \\ Pretoria, Private Bag X20, Hatfield 0028, South Africa
}

January 30,2018 


\section{Highlights}

- Propeller ice impacts are measured on the shaft-line of an ice-going vessel.

- An inverse problem is solved to estimate impact-induced moments at the propeller.

- Five ice-induced load cases are presented.

- The maximum allowed ice-induced propeller torque was marginally not exceeded.

- Regularization methods crucially influence the appraisal of safe design margins. 


\section{Abstract}

In order to estimate the forces exerted on ship propellers during ice navigation, the rotational dynamics of the propulsion system need to be accurately modelled. The blade measurements of ice loads on the propellers of ships during ice navigation is challenged by the harsh operating environment. Shaft line measurements are therefore performed inboard, and the required propeller loads are subsequently estimated through the use of a dynamic model and the solution of an inverse problem. The inverse problem is mathematically ill-posed and requires the determination of the ice-induced load on the propeller blade from shaft line measurements. The present study investigated full-scale torsional responses on the shaft line of a polar supply and research vessel during navigation through sea ice on a 68-day voyage between Cape Town and Antarctica. The vessel spent almost 11 days in ice with observed concentrations above $90 \%$ and a maximum thickness of 3 meters. The aim was to evaluate the extreme ice-induced moments on the shaft line and thereby determine how sparsely published operational loadings compare to the design loads of an ice-going vessel. Ice-induced moments on the propeller were obtained from operational measurements through three previously published approaches to solving the ill-conditioned inverse problem. The regularization methods used included truncated Singular Value Decomposition, truncated Generalized Singular Value Decomposition and Tikhonov regularization. The maximum ice-induced external moment was found to be $941.5 \mathrm{kNm}$, which was just within the maximum allowed ice-induced torque on the propeller. The duration of ice impacts on the propeller ranged from 25 to 228 milliseconds. A secondary peak was evident in torsional responses obtained from propeller-ice impacts which is thought to be a shear stress wave that propagates and reflects back in the shaft line. From the inversely determined ice-induced loads, the number of impacts, the duration, the shape and the damping of water on the propeller was identifiable. The results obtained were physically reasonable, indicating that the current methods are suitable for obtaining ice-induced loading on the propeller from shaft line measurements.

\section{Keywords}

Full-scale measurements; Ice-induced propeller loads; Shaft line torque; Inverse problem; Regularization

\section{Introduction}

Efficient and safe shipping in Arctic regions is an increasing requirement as maritime transport in ice-covered seas is expected to increase in future decades [1], [2]. The main source of excitation for polar class propulsion 
systems is attributed to propeller-ice interaction [3]. The International Association of Classification Societies (IACS) [4] which encompasses the Korean Register [5], American Bureau of Shipping [6], Det Norske Veritas (DNV) [7], Lloyd's Register [8] and Finnish-Swedish Ice Class Rules' Guidelines [9], amongst a few, has formulated rules for Polar Class (PC) ships intended for Arctic navigation. These regulations have been integrated to obtain the classification of ice going vessels [3]. Detailed and reliable full-scale measurement data sets assist to improve such regulations, which lead to interest in the effect of ice loads on the propulsion systems of ships $[10,11]$.

During ice passage, the first element of the propulsion machinery to interact with ice is the propeller. Subsequently, ice-related loads are transferred to other elements of the transmission system [12]. In a year long study on Baltic shipping Hänninen [13] reported that $35 \%$ of maritime-related accidents pertained to propeller damage [13]. Ice navigation subjects the propeller to non-contact loads, which includes the hydrodynamic load on the blade experienced in open water conditions and contact loads, which comprise ice milling, crushing and ice impact [3]. Ice milling is defined as the process during which multiple blades impact an ice floe [14]. Crushing describes the situation where ice is pressed onto the blade until it crushes which results in high loads [15]. Smaller ice debris that result in more moderate loads and which are passed through the propeller are referred to as ice impacts [3].

Propeller loads could ideally be determined directly from blade measurements [1]. However, the challenges to this approach include the interaction of the blades with the working environment as well as ice impacts that damage the sensors [16]. Besides this, the installation costs involved are high due to the requirement of cable ducting through the shaft to the propeller blades [1].

Current full-scale measurements of ice loads rely on shaft line measurements through strain gauges, which are installed inboard, between the propeller and the engine [11]. With this approach ice-induced moments are not measured directly and include the dynamic response of the mechanical transmission elements [12]. To determine propeller loads from shaft line measurements, the transfer function between the externally induced loads and the internal shaft line measured torque is to be determined. One of the most commonly used methods in torsional vibration analyses includes the simplification of transmission systems to lumped mass models as shown in studies by Ikonen[1], He [17] and Det Norske Veritas [7]. Inverse methods are subsequently required to perform indirect force determination of ice-loading on the propeller blades.

The complication with the discretization of inverse problems is that this leads to an ill-conditioned coefficient matrix for the system of linear equations, which require regularization methods to obtain stable solutions [18]. Regularization is the procedure whereby a problem is modified to reduce the sensitivity of the response 
and obtain a robust solution [19]. Suominen et al. [20] and Bekker et al. [21] performed inboard shaft line measurements on the polar supply and research vessel, SA Agulhas II. Ikonen et al. [1] proceeded to demonstrate the solution of an ill-conditioned inverse problem through three approaches including Truncated Singular Value Decomposition (TSVD), Truncated Generalized Singular Value Decomposition (TGSVD) and Tikhonov regularization. The findings indicated that these methods are capable of solving the ice moment function for a set of verification data and in load cases where up to four consecutive ice contacts were present. Myklebost and Dahler [22] reported disturbances on the shaft line measurement system of the SA Agulhas II which inhibited the evaluation of full voyage data. This was rectified by De Waal [23] who installed and validated a new measurement system on the same vessel, capable of gathering trustworthy data.

The aim of the present investigation was to verify the existing inverse estimation algorithm for ice-induced torque presented by Ikonen et al. [1] and to use this algorithm to determine and publish propeller-ice loading from trustworthy shaft line measurements on an operational voyage of the SA Agulhas II to Antarctica. In particular, ice milling cases and associated ice conditions were investigated as well as the implications of different regularization methods on the interpretation of extreme loading conditions.

\section{Full-scale measurements}

\subsection{SA Agulhas II}

The polar supply and research vessel, SA Agulhas II (SAA II) (Figure 1) is propelled by two Conver Team electric motors of 4.5 MW each. Each motor is connected to a propulsion shaft with four-bladed variable pitch propellers [24]. Four $3 \mathrm{MW}$ diesel generators are used to supply propulsion power. The ship was manufactured in Rauma shipyard in 2012 by STX Finland [21] with an ice-strengthened hull in accordance with DNV ICE-10. She is classified to Polar Ice Class PC-5 [25] and therefore rated for year-round operations in medium first-year ice containing old ice inclusions [4]. Further specifications of the vessel are presented in Table 1. 


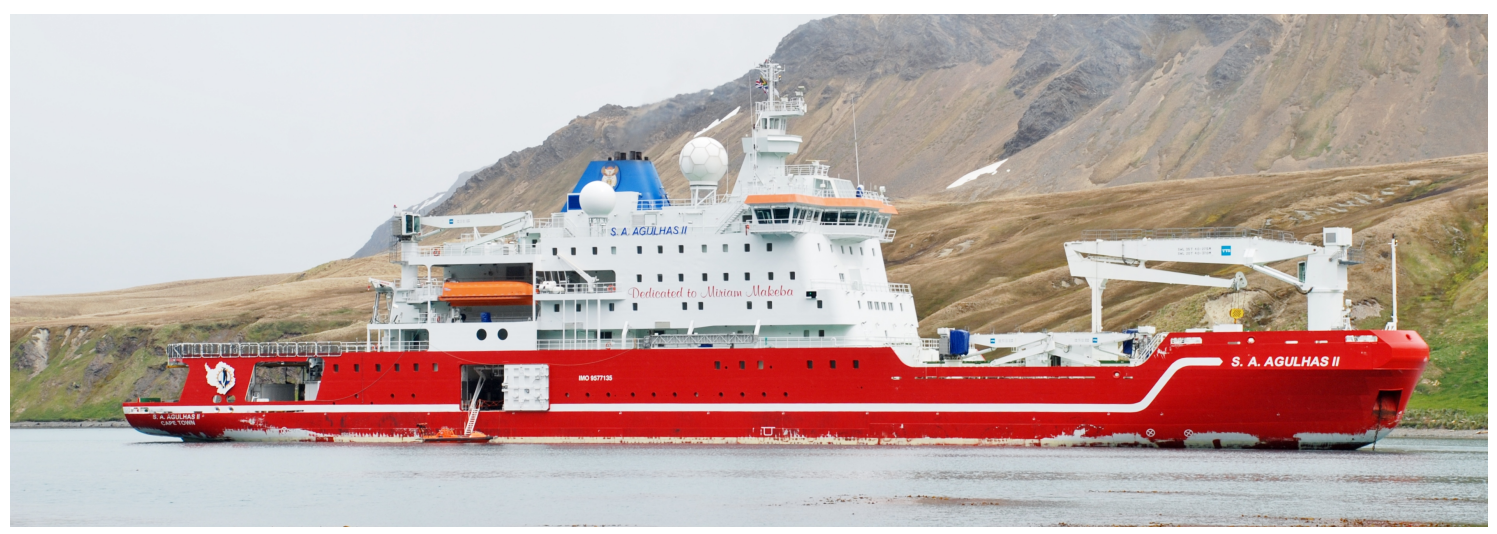

Figure 1: SAA II vessel instrumented during the 2015/2016 voyage to Antarctica.

Table 1: Vessel specifications [24].

\begin{tabular}{lc|lc}
\hline Gross tonnage & $12897 \mathrm{tons}$ & Diesel engine type & 6L32 \\
Length & $134 \mathrm{~m}$ & Electric motor type & N3 HXC 1120 LL8 \\
Breadth & $22 \mathrm{~m}$ & Speed $(\mathrm{n})$ at MCR & $140 \mathrm{rpm}$ \\
Classification & DNV & Power $\left(P_{D}\right)$ at MCR & $4500 \mathrm{~kW}$ \\
Class notation & 1A1 PC-5/ICE-10 & Nominal torque $\left(Q_{M C R}\right)$ & $307 \mathrm{kNm}$ \\
Yard/Year & STX Finland/2012 & Propeller maker & Rolls-Royce \\
Main engine maker & Wärtsilä & No. of blades/Diameter & $4 / 4.3 \mathrm{~m}$ \\
\hline
\end{tabular}

\subsection{Antarctic voyage}

Full-scale measurements were performed during the 2015/2016 voyage of the SAA II from Cape Town to Antarctica. Shear strain and axial strain measurements were captured along with, machine control, radial bearing vibration, ice conditions and navigation data. The GPS track of the voyage is presented in Figure 2. During the 2015/2016 voyage:

- The vessel departed Cape Town harbour (1) on 5 December 2015 and headed towards the Greenwich Meridian, along which she navigated to Antarctica (3).

- Ice was encountered on 11 December 2015 and continued until 16 December when she arrived at the shelf, Penguin Bukta (3).

- On 22 December she navigated to Akta Bukta near the German Antarctic Research Station, Neumayer.

- From Akta Bukta she headed through heavy pack ice towards the South Sandwich Islands and arrived at South Thule (4) on 24 December.

- After South Thule, she navigated out of the ice field and reached South Georgia (5) on 30 December 2015. Her journey back to Antarctica started on the same day. 
- She re-encountered ice on 11 January on route to Penguin Bukta (3).

- The voyage back to Cape Town started on 1 February. She left the ice field on 2 February and arrived in Cape Town on 11 February 2016.

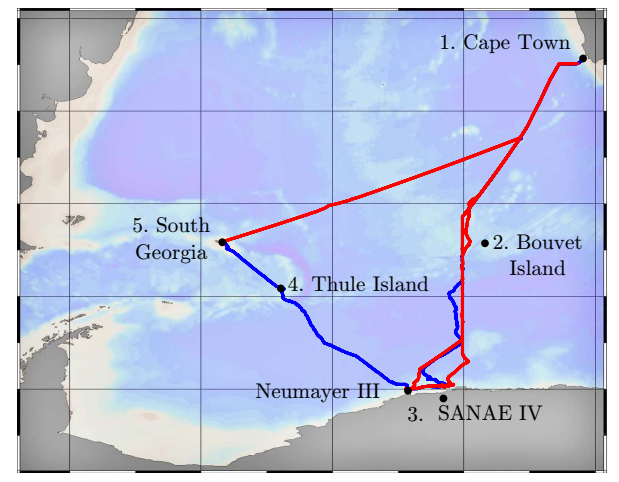

Figure 2: Round voyage for the SAA II to Antarctica (Blue - outbound, red - return voyage).

The total voyage lasted 68 days, of which 10.7 days were spent navigating in ice, 40 days navigating in open water and 17.5 days stationary. The pie chart in Figure 3 depicts the operational profile of the vessel. The ice conditions varied throughout the voyage and are summarised in Figure 3.

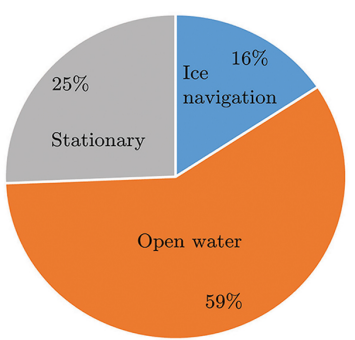

(a)

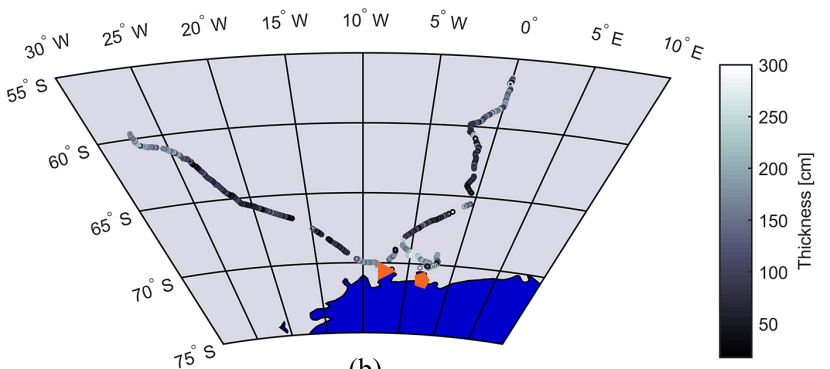

(b)

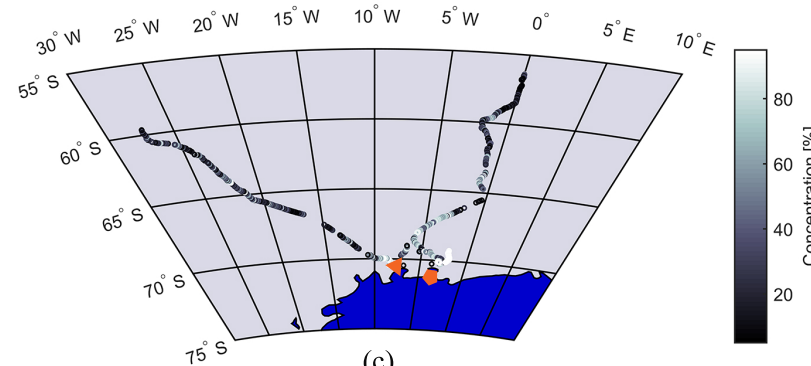

(c)

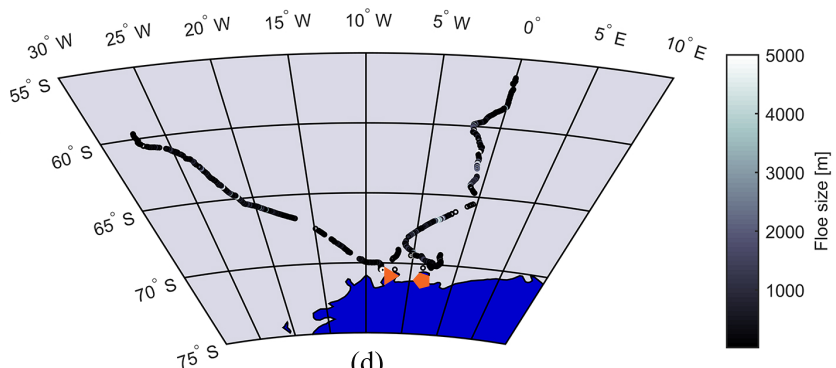

(d)

Figure 3: The (a) operational profile and ice conditions, including (b) thickness (c) concentration and (d) floe size encountered by the SAAII on the 2015/2016 Antarctic relief voyage. 


\subsection{Instrumentation}

Strain gauges were installed on the port side intermediate shaft line, $25.9 \mathrm{~m}$ from the center of gravity of the propeller (Figure 4), to determine torque loading from strain gauge measurements. The strain gauges were connected in a Wheatstone bridge configuration to reject axial strain, compensate for temperature variations and reject bending. This was achieved by installing two pairs of T-rosette strain gauges on diametrically opposing sides of the shaft. The gauges were inclined at $\pm 45^{\circ}$ with respect to the horizontal mid-plane of the shaft in order to measure the maximum shear stress on the outer surface (Figure 5a). A V-link lossless extended range synchronized (LXRS) system, produced by LORD MicroStrain, was installed to transmit the measurements wirelessly (Figure 5b) to a HBM Quantum mobile data acquisition system. The HBM Quantum was connected to a laptop via an ethernet cable and recorded through Catman AP V3.5 software at a sample rate of $600 \mathrm{~Hz}$.

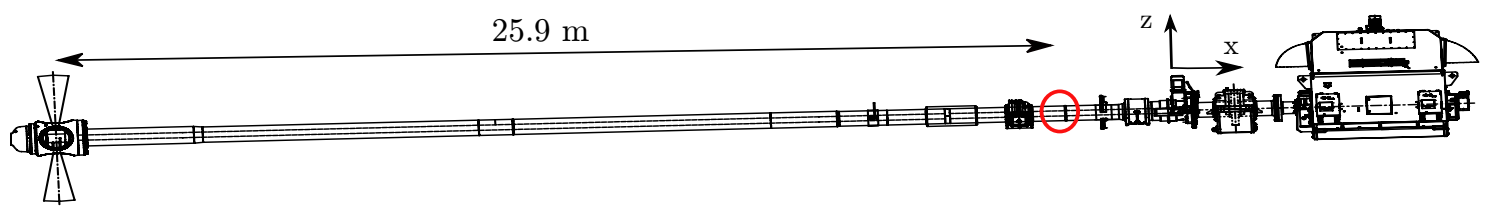

Figure 4: Location of strain gauges mounted along the shaft line. Adapted from [24].

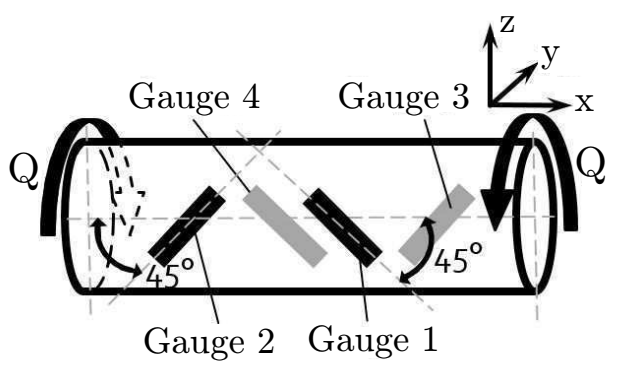

(a)

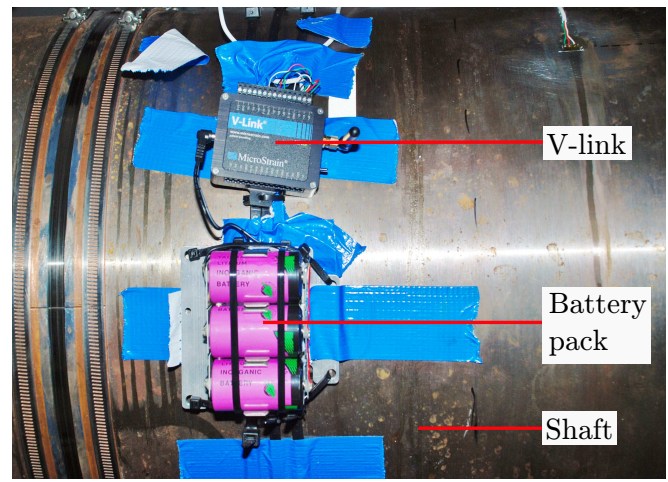

(b)

Figure 5: Shaft line measurements with (a) strain gauge placement (Adapted from [26]) and (b) measurement setup.

The general equation used for a Wheatstone full bridge configuration [26] is expressed in terms of $U_{E}$ which is the supply voltage and $U_{A}$, the bridge output voltage as a result of operational shaft deformations. The gauge factor, $k=1.99$, is supplied on the packaging and $\varepsilon_{i}$ (where $i=1,2,3,4$ ) represent the strain measurements from the gauges 1,2,3 and 4 of the Wheatstone bridge. When torque is applied as indicated in Figure 5b, strain gauge number 2 and 4 will sense negative strain and strain gauge 1 and 3 will sense an equal 
but positive strain. Thus, the absolute value of the measured strains $\left(\varepsilon_{1}\right.$ to $\left.\varepsilon_{4}\right)$ will be equal and additive.

$$
\frac{U_{A}}{U_{E}}=\frac{k}{4}\left(\varepsilon_{1}-\varepsilon_{2}+\varepsilon_{3}-\varepsilon_{4}\right)=k \varepsilon
$$

It can be shown that the torque in the hollow shaft, $Q_{\text {shaft }}$, is related to the Young's Modulus, $E$, Poisson's ratio, $\nu$, outer- $\left(d_{o}\right)$ and inner $\left(d_{i}\right)$ shaft diameters and Wheatstone bridge output voltage:

$$
Q_{\text {shaft }}=U_{A} \frac{\pi E\left(d_{o}^{4}-d_{i n}^{4}\right)}{16 U_{E} k d_{o}(1+\nu)}
$$

The shaft dimensions for the SAA II were obtained from engineering drawings by STX Finland [24]. The material specifications were sourced from Rolls-Royce [27] which provided parameters for numerical calculations during the propulsion system design phase. The dimensions, material properties and shaft related variables are presented in Table 2 . The depth of the propeller centerline, $h_{o}$, was not directly obtainable from engineering drawings and was inferred from scaled vessel drawings.

Table 2: Shaft line dimensions, material properties and shaft related variables for the measurement locations $[24,27,28,29,7]$.

\begin{tabular}{lll|lll} 
Description & Symbol & Value & Description & Symbol & Value \\
\hline Modulus of elasticity & $E$ & $210 \mathrm{GPa}$ & Max ice thickness & $H_{i c e}$ & $2.0 \mathrm{~m}$ \\
Shear modulus & $G$ & $81 \mathrm{GPa}$ & Ice strength index & $S_{i c e}$ & $1.1 \mathrm{~m}$ \\
Outer diameter & $d_{o}$ & $0.5 \mathrm{~m}$ & Pitch at & $P_{0.7}$ & $5.15 \mathrm{~m}$ \\
Inner diameter & $d_{i n}$ & $0.175 \mathrm{~m}$ & Expanded blade area ratio & $E A R$ & 0.51 \\
Hub diameter & $d_{h}$ & $1.32 \mathrm{~m}$ & Depth of propeller centerline & $h_{o}$ & $3.75 \mathrm{~m}$ \\
\hline
\end{tabular}

\section{Method}

Ice loading on the propeller is to be determined from shaft line measurements on a polar research vessel. This is achieved through a two-step process. Firstly, a forward problem is solved whereby the dynamic model is subjected to a step impulse moment at the propeller. The impulse response function between the externally applied ice moment on the propeller and the internal torque response in the shaft line is thereby determined at the measurement location. Secondly, an inverse problem is solved to determine externally applied propeller moments from the measured shaft line torque and ill-posed inverted impulse response. 


\subsection{Dynamic model}

A simplified dynamic model of the torsional dynamic response of the SAA II was obtained by using a lumped mass model documented by Rolls-Royce [30] and Ikonen et al. [1]. This was done to determine the impulse response function, which describes the strain gauge output when a unit moment is applied, at $t=0$, to the propeller. The governing matrix equation for the torsional response of a mass-damper system is:

$$
\mathbf{J} \ddot{\bar{\theta}}+\mathbf{C} \dot{\bar{\theta}}+\mathbf{K} \bar{\theta}=\bar{Q}(t)
$$

Here, $\mathbf{J}$ is a matrix containing entries, which relate to the polar moment of inertia, $\mathbf{C}$, the damping, $\mathbf{K}$, the rigidity, $\bar{Q}$, the generalized excitation torque vector and $\bar{\theta}$, the angular displacement vector of the twisting angles at the system nodes.

A diagram of the lumped-mass model for the SAA II shaft line is presented in Figure 6. $J_{1}$ represents the controllable pitch propeller (CPP), $J_{3}$ the mid-propeller shaft, $J_{5}$ the sleeve coupling, $J_{7}$ the oil distribution box flange, $J_{9}$ the thrust shaft collar, $J_{11}$ the electric motor flange and $J_{13}$ the propulsion motor. The hydro-dynamic damping on the rotating propeller is modelled by $c_{1}$ whereas $c_{2}, c_{4}, \ldots, c_{12}$ and $k_{2}, k_{4}, \ldots, k_{12}$ respectively represent the shaft line damping and torsional stiffness. $Q_{\text {shaft }}$ represents the shaft torque, which can be calculated from full-scale measurements using Eq.2. Inverse methods are subsequently required to determine the ice-induced moment at the propeller, $Q_{i c e}$. The variables used for the dynamic model were obtained from Rolls-Royce [30] and are presented in the Appendices.

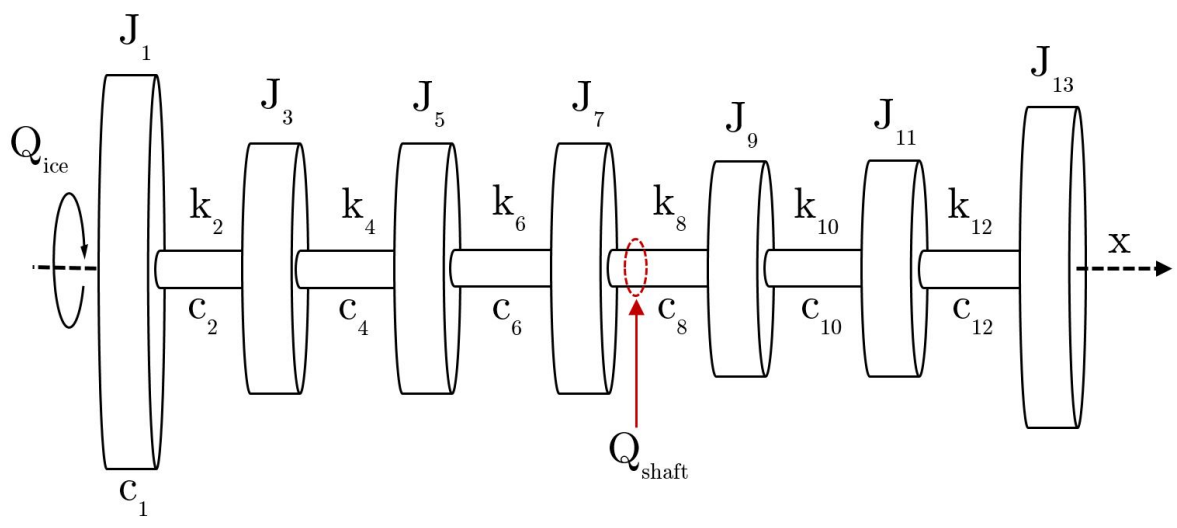

Figure 6: A diagram of the dynamic model for the SAA II shaft line comprising inertia, damping and torsional spring elements. 


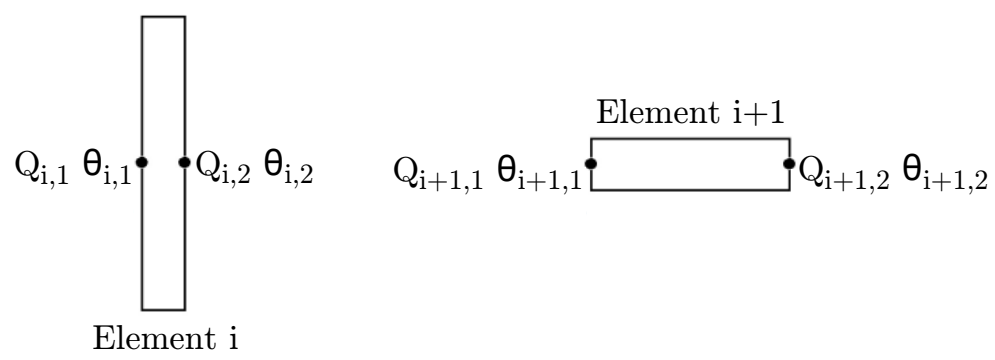

Figure 7: Elements and relative nodes. Adapted from Ikonen et al. [1].

The lumped mass model was solved by considering rotational degrees of freedom about the longitudinal shaft axis (x-axis). The model elements comprised inertia elements and shaft elements, which each contained two nodes as shown in Figure 7. Each node is associated with a torsional moment, $Q$, and angular displacement, $\theta$. Using the governing equation of torsional vibration in Eq. 3, Eq. 4 can be derived for inertia elements (odd values of $i$ ) and Eq. 5 for torsional spring elements (even values of $i$ ):

$$
\begin{gathered}
J_{i} \ddot{\theta}_{i, 1}+c_{i} \dot{\theta}_{i, 1}=-Q_{i, 1}+Q_{i, 2}+Q_{i c e} \\
c_{i}\left(\dot{\theta}_{i, 2}-\dot{\theta}_{i, 1}\right)+k_{i}\left(\theta_{i, 2}-\theta_{i, 1}\right)=Q_{i, 1}
\end{gathered}
$$

with $i$ being the increment for the thirteen elements of the shaft line system. Subscript $(i, 1)$ denotes the value of the variable on the left side of the element and subscript $(i, 2)$ on the right side of the element. For inertia elements, the angular displacement on the right and left side are equal, and therefore $\theta_{i, 1}=\theta_{i, 2}$. For spring elements, the internal torque remains constant and therefore $Q_{i, 1}=Q_{i, 2}$.

Direct integration methods could be used to obtain approximate solutions of dynamic systems [31]. Two principal approaches to multi-degree of freedom direct integration methods are the explicit and implicit schemes [32]. For an explicit scheme, previously determined values of displacement, velocity and acceleration are used to determine the response quantities [32]. Implicit schemes combine the equations of motion with difference equations to calculate the displacement directly [32]. Implicit schemes involve iterative procedures for each time step, making them more computationally intensive [31]. The disadvantage of explicit schemes is that they are conditionally stable relative to the size of the selected time step whereas implicit schemes can be either conditionally or unconditionally stable [31]. Wilson [31] recommends that single-step, implicit, unconditionally stable methods should be used for step-by-step analysis of practical structures. To this end the unconditionally stable Newmark-Beta method was used for direct integration in the time domain as outlined by Ikonen et al. [1].

The dynamic model was solved by first defining an integration formula for the angular velocity $\dot{\theta}$ and angular 
acceleration $\ddot{\theta}$ through the Newmark-Beta method [31]. The dynamic problem could then be solved by combining the Newmark-Beta integration method and an incremental form of the governing equation of torsional vibration. For a more detailed procedure, the reader is encouraged to refer to [23] and [1]. All calculations were performed using custom algorithms programmed in MATLAB.

\subsection{Inverse method validation}

The principle of superposition [33] can be used to model the response of linearly elastic dynamic systems. The relationship between the shaft torque and ice-induced moment is expressed in Eq. 6, referred to as the convolution integral, which represents the dependency between the loading on the propeller, $Q_{i c e}$, and the response measured on the shaft line, $Q_{\text {shaft }}$. $H$ is the impulse response function between the loading point at the propeller and the measurement location on the shaft. The impulse response function is shifted by the variable of integration $\Phi$ to represent a random load history as a series of impulses [33]:

$$
Q_{\text {shaft }}(t)=\int_{0}^{t} H(t-\Phi) Q_{\text {ice }}(\Phi) d \Phi
$$

Equation 6 can be solved by transforming it into a system of linear equations and discretizing the integral into time steps, resulting in Eq.7 [19]:

$$
\bar{Q}_{\text {shaft }}(t)=\mathbf{H}(\mathbf{t}) \bar{Q}_{i c e}(t)
$$

Here, $\mathbf{H}$ is the impulse response matrix representing the transfer function between the loading point at the propeller and the measurement location on the shaft, and $\bar{Q}_{s h a f t}$ and $\bar{Q}_{i c e}$ respectively represent the shaftand ice-induced moment vectors. In order to solve for the unknown ice-induced moment vector, $\bar{Q}_{i c e}$, from shaft line measurements, $\bar{Q}_{\text {shaft }}$, Eq. 7 is rearranged, as presented in Eq. 8. This results in the requirement to solve an inverse problem in order to determine the causal factors that produce the observed response.

$$
\bar{Q}_{i c e}(t)=\mathbf{H}^{-\mathbf{1}}(\mathbf{t}) \bar{Q}_{\text {shaft }}(t)
$$

The complication with the discretization of inverse problems is that this leads to an ill-conditioned coefficient matrix for the system of linear equations, which require regularization methods to obtain stable solutions [18]. Regularization is the procedure whereby the initial problem is modified to reduce the sensitivity of the response towards a robust solution [19]. To this end three inverse methods have been investigated to 
perform inverse moment determination in an impact loading situation of the dynamic shaft line structure. In keeping with the approach of Ikonen et al. [1] three regularization methods, namely Truncated Singular Value Decomposition (TSVD), Truncated Generalized Singular Value Decomposition (TGSVD) and Tikhonov regularization were implemented.

TSVD is a common method used to regularize ill-posed systems. The SVD of $\mathbf{H} \in \mathbb{R}^{m \times n}$, where $m \geq n$, can be defined as [34]:

$$
\mathbf{H}=\mathbf{U} \boldsymbol{\Sigma} \mathbf{V}^{\mathbf{T}}=\sum_{i=1}^{n} \bar{u}_{i} \sigma_{i} \bar{v}_{i}^{T}
$$

Here, $\mathbf{U}$ is a matrix of orthonormalized eigenvectors of $\mathbf{H H}^{\mathbf{T}}$ and $\mathbf{V}$ comprises the orthonormalized eigenvectors of $\mathbf{H}^{\mathbf{T}} \mathbf{H}$. Furthermore, $\boldsymbol{\Sigma}$ is a diagonal matrix containing non-negative singular values of $\mathbf{H}$ in decreasing order. As expressed in Eq.9 the solution of the system depends on the singular values, $\sigma_{i}$, and singular vectors $\left(\bar{u}_{i}\right.$ and $\left.\bar{v}_{i}\right)$ of $\mathbf{H}$. TSVD aims to reduce the rank of the matrix, $\mathbf{H}$, by eliminating small singular values, thereby obtaining a closest well-conditioned approximation. This is achieved by evaluating the magnitude of the singular values. If a discontinuity occurs where the singular values decrease rapidly in magnitude, the larger singular values are retained and the remainder are set equal to zero [35]. Eq. 9 can be rewritten to obtain the desired solution through the TSVD method, where, $j$, represents the number of singular values retained [35] and $\bar{q}_{s}$ is the internal shaft torque:

$$
\bar{Q}_{i c e}=\sum_{i=1}^{j} \frac{\bar{u}_{i}^{T} \bar{q}_{s}}{\sigma_{i}} \bar{v}_{i}, \quad j \leq n
$$

Truncated Generalized Singular Value Decomposition (TGSVD) is a more sophisticated method whereby further information about the desired solution can be incorporated to stabilize the problem [19]. This is achieved through the regularization matrix, $\mathbf{L}$, which often takes the form of the first or second derivative operator [18]. Ikonen et al. [1] found that the first order regularization matrix (Eq. 11) is well-suited to smooth the obtained propeller moment solution. It should be noted that, since the elements of the solution correspond to changes in the ice-induced moment vector, $\bar{M}=\left[\Delta m_{1} \Delta m_{2} \Delta m_{3} \ldots \Delta m_{n}\right]^{T}$ the regularization in fact corresponds to smoothing the solution by the second order derivative.

$$
\mathbf{L}=\left[\begin{array}{ccccc}
-1 & 1 & 0 & \cdots & 0 \\
0 & -1 & 1 & \cdots & 0 \\
\vdots & \vdots & \ddots & \ddots & \vdots \\
0 & 0 & \cdots & -1 & 1
\end{array}\right]
$$


The system can be represented by the real matrix pair $\left(\mathbf{H} \in \mathbb{R}^{m \times n}\right.$ and $\left.\mathbf{L} \in \mathbb{R}^{p \times n}\right)$ with $m \geq n \geq p$ [36]:

$$
\begin{gathered}
\mathbf{H}=\mathbf{U}\left[\begin{array}{cc}
\boldsymbol{\Sigma} & 0 \\
0 & \mathbf{I}_{\mathbf{n}-\mathbf{p}}
\end{array}\right] \mathbf{X}^{-\mathbf{1}} \\
\mathbf{L}=\mathbf{V}(\bar{M}, 0) \mathbf{X}^{-\mathbf{1}}
\end{gathered}
$$

Here, $\mathbf{U} \in \mathbb{R}^{p \times r}$ and $\mathbf{V} \in \mathbb{R}^{q \times q}$, which have orthonormal columns. Therefore, $\mathbf{U U}^{\mathbf{T}}=\mathbf{I}_{r}$ and $\mathbf{V}^{\mathbf{T}} \mathbf{V}=\mathbf{I}_{q}$. Furthermore, $\mathbf{X} \in \mathbb{R}^{r \times r}$ is a non-singular matrix.The desired solution can be obtained by applying TGSVD, which is similar to TSVD wherein the number of singular values is reduced to $j$ [35]:

$$
\bar{Q}_{i c e}=\sum_{i=p-j+1}^{p} \frac{\bar{u}_{i}^{T} \bar{q}_{s}}{\sigma_{i}} x_{i}+\sum_{i=p+1}^{n}\left(\bar{u}_{i}^{T} \bar{q}_{s}\right) x_{i}
$$

Another widely used regularization method is Tikhonov's regularization method, which involves the solution of a least squares problem. This method is convenient for problems in which both the coefficient matrix and the required solution can only be determined approximately [18]. This method filters out the unwanted components corresponding to small singular values by adding damping to each TSVD component of the solution [18]. The formulation of Tikhonov's method is [18]:

$$
\min \left\{\left\|\mathbf{H} \bar{Q}_{i c e}-\bar{Q}_{\text {shaft }}\right\|_{2}^{2}+\lambda\left\|\mathbf{L} \bar{Q}_{i c e}\right\|_{2}^{2}\right\}
$$

Here $\lambda$ is a positive constant referred to as the regularization parameter. The required solution for the ice moment vector, $\bar{Q}_{i c e}$, minimizes Equation 15 .

To validate the custom algorithms in MATLAB, known moment impulses were applied at the propeller and the associated shaft response was determined (forward problem) [1]. The known moment impulses included both, a linear moment impulse and a half-sine impulse stimulus to simulate single ice impacts. Consecutive linear and half-sine moment impulses were also evaluated to investigate multiple impacts. Some noise is subsequently added to the calculated shaft responses and inverse methods are used to extract the calculated ice-induced moments.

The inverse calculation of the moment impulse further serves to determine the optimum regularization parameters. In this step, the L-curve is investigated. This curve expresses the semi-norm as a function of the residual norm. The optimal level of regularization is located at the "knee" of the curve. Excessive regularization will result in an inversely calculated solution that will not approximate the known moment impulse 
properly. Insufficient regularization will result in a solution, which will approximate the known moment impulse but will be dominated by the contribution of data errors [34]. The L-curve is therefore used to find the best compromise between insufficient and excessive regularization..

\subsection{Ice-impacts from full-scale measurements}

Case studies of ice-impacts were selected from operational data. Specifically, cases were selected to allow the study of multiple ice impacts and to investigate the maximum torsional loading of the shaft line of the polar vessel. The stability of the inverse methods is investigated for transient torque values from full-scale measurement data, $\bar{Q}_{\text {shaft }}$. In order to determine the loading contribution of ice impact, the hydrodynamic torque was subtracted from the measured internal torque and the direction of the moment inverted to obtain a positive external ice-induced moment on the propeller. It was further evaluated if the estimated ice moment could again be inverted to match the measured shaft torque value. This inverted internal torque was obtained by determining the relevant external moment through the Tikhonov method and using this result as an input to the dynamic model to obtain the internal torque (by solving the forward problem).

\section{Results and analyses}

\subsection{Dynamic model}

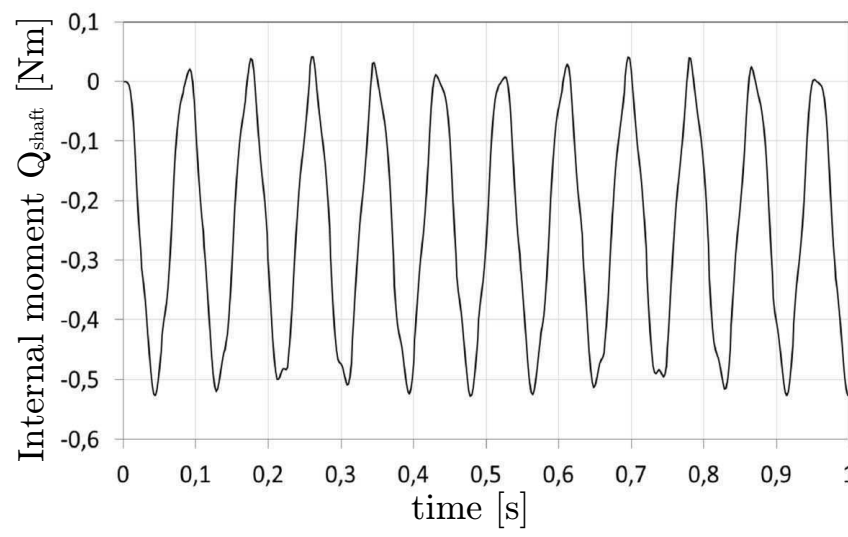

(a)

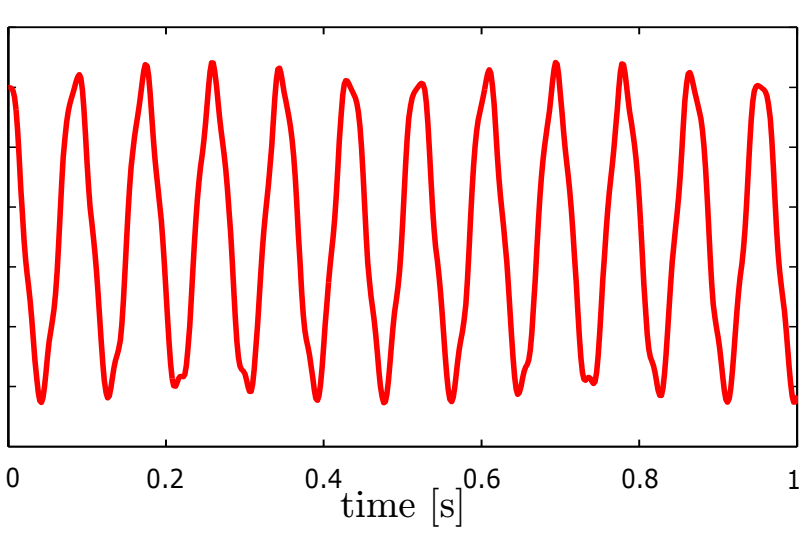

(b)

Figure 8: Resultant internal torque on shaft line element 8 from a unit step input applied to the propeller through the dynamic model. This response was determined without damping. Results obtained by (a) Ikonen et al. [1] and (b) present research.

A forward problem was solved to determine the internal torque response in shaft line element eight, $Q_{\text {shaft }}$, for a unit step input, $Q_{i c e}$ and no damping as presented in Figure 8. This result was compared to the result 
obtained by Ikonen et al. [1] for verification. The two graphs are identical indicating that the current implementation of the lumped mass model is able to replicate the work of Ikonen et al. [1]. The torsional natural frequencies of the SAA II shaft line have been determined by Bekker et al. [21] to be $11.2 \mathrm{~Hz}$ and $46.3 \mathrm{~Hz}$. The natural frequencies determined by Ikonen et al. [1] are compared to those determined in the present study in Table 3.

Table 3: Comparison of natural frequencies determined numerically through current model and by [1] to natural frequencies determined through full-scale measurements by [21].

\begin{tabular}{lccc} 
& Bekker et al. [21] & Ikonen et al. [1] & Current model \\
\hline$f_{1}$ & $11.2 \mathrm{~Hz}$ & $11.5 \mathrm{~Hz}$ & $11.5 \mathrm{~Hz}$ \\
$f_{2}$ & $46.3 \mathrm{~Hz}$ & $48.2 \mathrm{~Hz}$ & $47.4 \mathrm{~Hz}$ \\
$\%$ error $f_{1}$ & & $2.7 \%$ & $2.4 \%$ \\
$\%$ error $f_{2}$ & & $4.1 \%$ & $2.3 \%$ \\
\hline
\end{tabular}

The difference in natural frequencies between the models is attributed to the use of slightly different lumped mass parameters by Ikonen et al. [1] compared to the variables used in the current model, based on manufacturer information [30].

\subsection{Ice-impacts from full-scale measurements}

The determination of the optimum levels of regularization for the TGSVD and Tikhonov regularization methods were determined through the L-curve. The optimum number of non-zero eliminated singular values for TGSVD was determined to be $n_{e}=120$ and the optimum regularization parameter for Tikhonov was determined to be $\lambda=24.57 \cdot 10^{-2}$. These parameters were very different to that of Ikonen et al. [1] as the compact truncated methods were used for the current model, as well as slightly different lumped mass model parameters as the current model parameters were directly obtained from Rolls-Royce documentation [27]. These regularization methods were implemented using algorithms written by Hansen [37]. Note that the external water damping, $c_{1}$ was re-instated for the inverse force calculations, although it was omitted in the step response determination in Section 4.1. More detailed analyses are presented by De Waal [23] and Ikonen et al. [1].

Five case studies were selected from operational data. The propeller pitch was approximately $88 \%$ for all cases with operating conditions as presented in Table 4. The observed ice concentration, thickness and floe size for the ten minute period surrounding the ice impacts are additionally reported in the table. Figure 9 presents photographs from the bow-facing view of the Bosch on-board camera system at the time when iceimpacts are recorded on the propeller. Cases 1, 2, 4 and 5 provide examples of ice impacts for navigation 
in waters with low ice concentration and small ice floes with thicknesses that exceed half a meter. Case 3 presents an example of ice passage through a large floe in an area with higher ice concentration.

Table 4: Operating conditions during four propeller-ice impact conditions. Case 1, 2 and 5 were extracted from data on 12 December, Case 3 on 13 December 2015 and the maximum ice impact condition, Case 4, on 11 December 2015. Average values of machine control data for the ice contact duration and hydrodynamic torque, $Q_{h}$, at the start of the ice contact condition are presented.

\begin{tabular}{|c|c|c|c|c|c|c|c|c|c|}
\hline Case & $\begin{array}{c}\text { Start } \\
\text { Time } \\
\text { [hh:mm:ss] }\end{array}$ & Speed & {$[\mathrm{kNm}]$} & $\begin{array}{l}\text { Motor } \\
\text { speed } \\
{[\mathrm{rpm}]}\end{array}$ & $\begin{array}{c}\text { Motor } \\
\text { power } \\
{[\mathrm{kW}]}\end{array}$ & $\begin{array}{c}\text { Propeller } \\
\text { pitch } \\
{[\%]}\end{array}$ & $\begin{array}{c}\text { Average ice } \\
\text { concentration } \\
{[\%]}\end{array}$ & $\begin{array}{c}\text { Ice } \\
\text { thickness } \\
{[\mathrm{cm}]}\end{array}$ & $\begin{array}{l}\text { Floe } \\
\text { size } \\
{[\mathrm{m}]}\end{array}$ \\
\hline Case 1 & $09: 27: 16$ & 5.0 & 219.2 & 109.0 & 2270.0 & 88 & 2 & 110 & 60 \\
\hline Case 2 & $09: 52: 52$ & 5.4 & 145.0 & 94.3 & 1313.3 & 88 & 12 & 70 & 30 \\
\hline Case 3 & $07: 46: 44$ & 6.6 & 310.7 & 130.0 & 4073.0 & 88 & 59 & 35 & 2420 \\
\hline Case 4 & $16: 50: 47$ & 3.8 & 222.1 & 85.1 & 670.3 & 70 & 21 & 110 & 15 \\
\hline Case 5 & 11:32:11 & 4.7 & 254.3 & 104.4 & 1830.0 & 88 & 10 & 54 & 60 \\
\hline
\end{tabular}

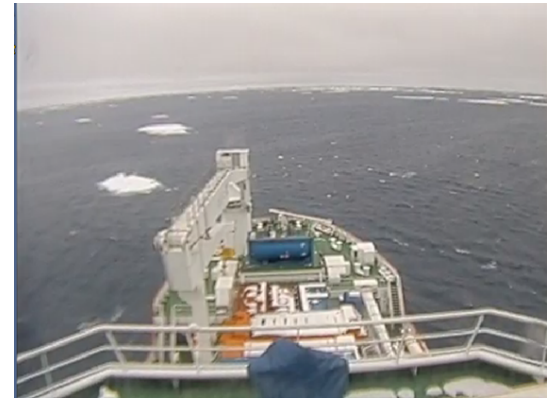

(a) Case 1 - 12 December 2015 09h27

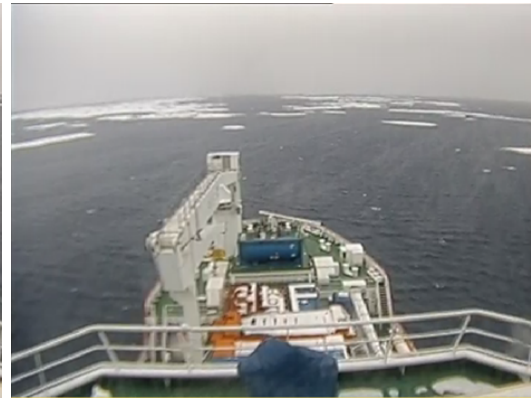

(b) Case 2 - 12 December 2015 09h52

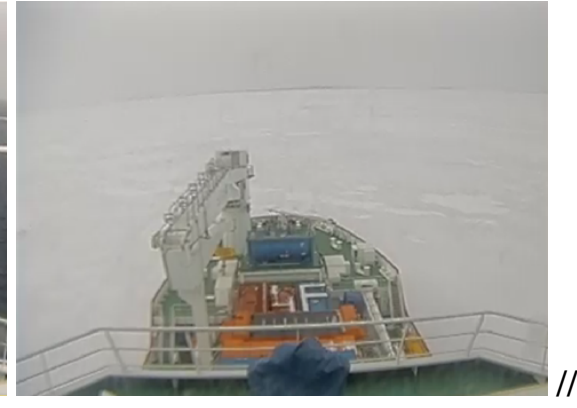

(c) Case 3 - 13 December 2015 07h46

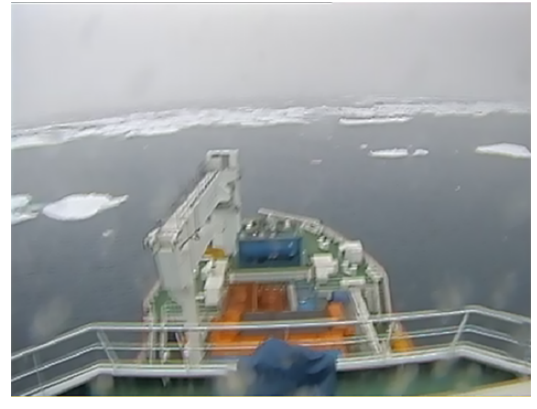

(d) Case 4 - 11 December 2015 16h50

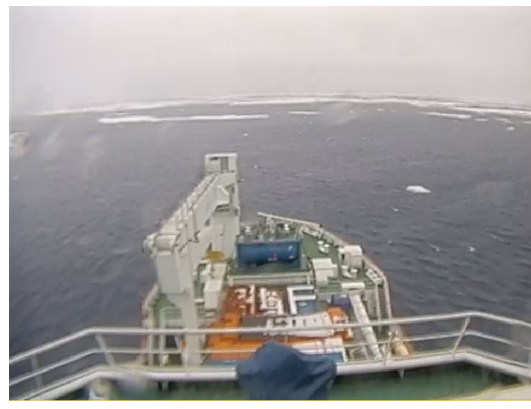

(e) Case 5 - 12 December 2015 16h50

Figure 9: Bow-facing photographs from the Bosch on-board camera system showing the observed ice conditions.

For discussion purposes the five case studies are grouped into moderate ice impacts, Cases 1 to 3 and maximum conditions, which relate to Cases 4 and 5 . 


\subsubsection{Moderate ice impacts: Case 1 to 3}

The measured internal torque is presented against the inverted torque in Figure 10 for three moderate ice impacts. The inverted torque follows the measured torque well (Figure 10), although sharp peaks are slightly damped as expected from the use of regularization methods.

Inverse methods were applied to the measurements from the three moderate propeller-ice impact cases to determine the relevant external propeller loads $Q_{i c e}$, presented in Figure 11. The optimal values for regularization parameters $n_{e}$ and $\lambda$ were determined through the L-curve and found to be the same as for the known moment impulses. All three methods provided similar results, except for Case 3 for which the Tikhonov regularization method resulted in a more oscillatory ice -induced moment $\left(Q_{i c e}\right)$ compared to the TSVD and TGSVD methods. From the known moment impulses, it was determined that Tikhonov followed the reference curve the best and therefore should provide the best representation of the inversed external moment.

From the inversely determined external moments, $Q_{i c e}$, the number of impacts, the duration, the shape and the damping of water on the propeller was identifiable. In general, an ice impact initiates a rapid increase in amplitude followed by a rapid decrease. However, the peak does not immediately damp down to zero for all cases. In Case 1, there are secondary peaks evident, which are usually smaller than the first. This secondary peak occurs between 15 and 47 milliseconds after the first peak for the current conditions. The cause of this secondary peak is explained [1] to be related to the shear stress wave that propagates back and forth from the propeller to the engine rotor. When this shear stress wave reaches the propeller again, it results in the blade of the propeller applying an impulsive load to the ice block. The propagation speed of a torsional wave in a linearly elastic medium is defined by [33]:

$$
c_{p}=\sqrt{G / \rho}
$$

where $G$ is the shear modulus of elasticity, $\rho$ the material density and $c_{p}$ the propagation speed. Using the variables from [27] for $G=81 \mathrm{GPa}, \rho=7850 \mathrm{~kg} / \mathrm{m}^{3}$ and [38], the propagation speed is $3212.2 \mathrm{~m} \mathrm{~s}^{-1}$. For the $35.1 \mathrm{~m}$ long shaft, this translates to a duration of approximately 11 milliseconds, the time it takes the wave to propagate back and forth along the shaft. This coincides with the smallest duration measured between the first and second peak in the external ice-induced moments. However, the exact location of the ice impact on the blade of the propeller and the propagation through the blade and shaft couplings is unknown, which could account for the longer propagation time for some of the secondary peaks. 


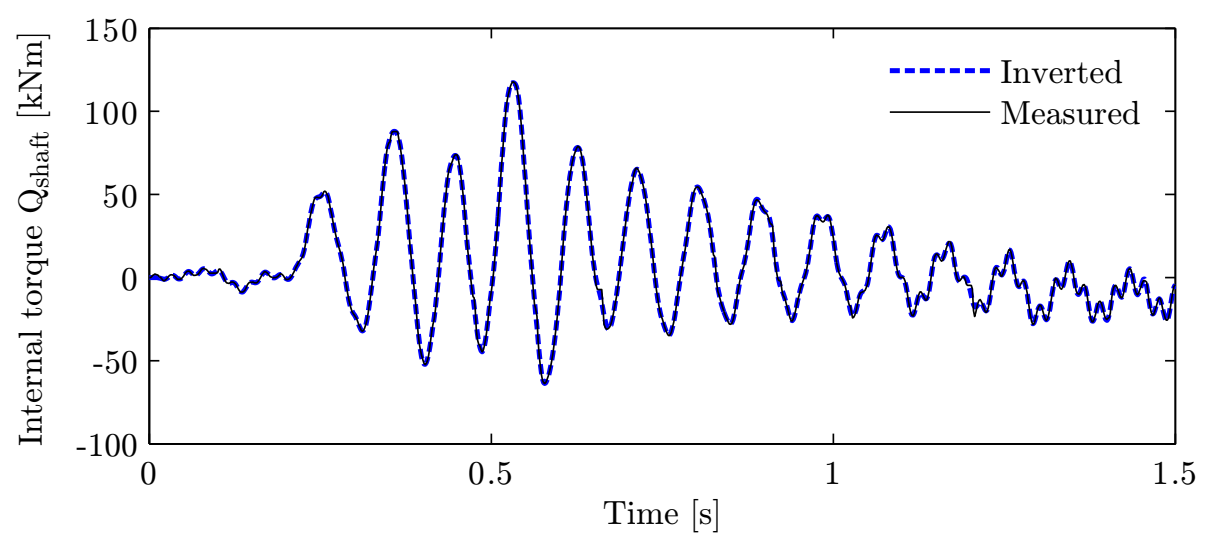

(a) Case 1

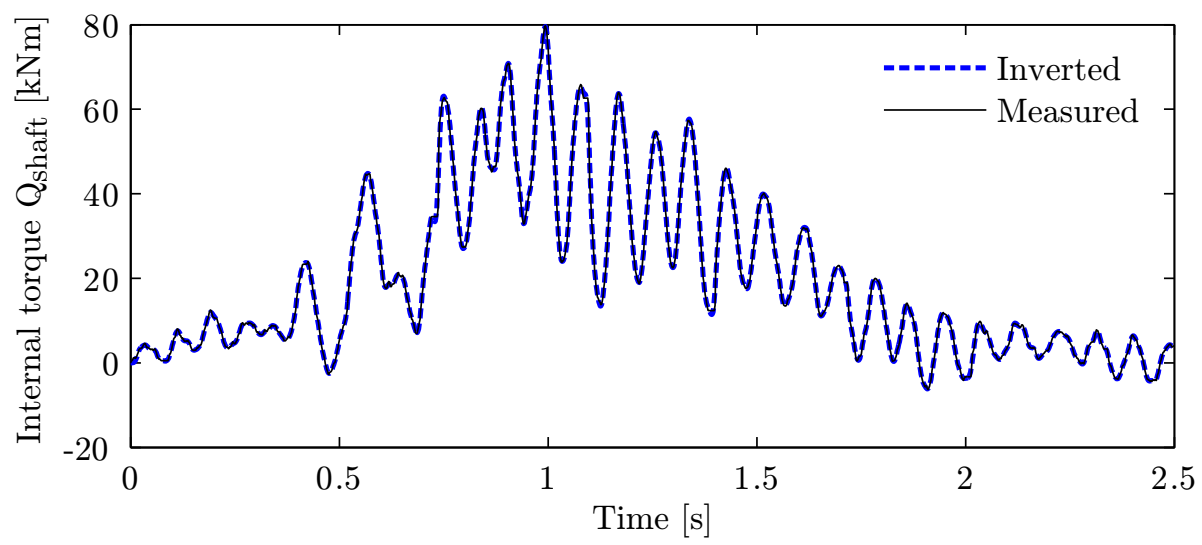

(b) Case 2

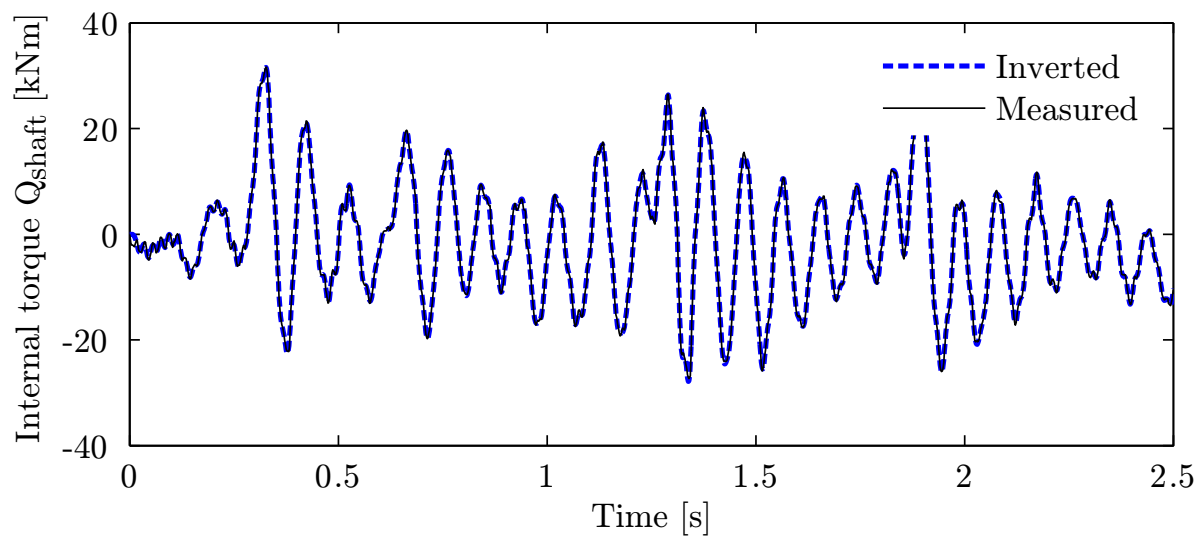

(c) Case 3

Figure 10: Measured internal torque and inversely determined internal torque for three propeller-ice impact cases of different durations and varying operating conditions. 


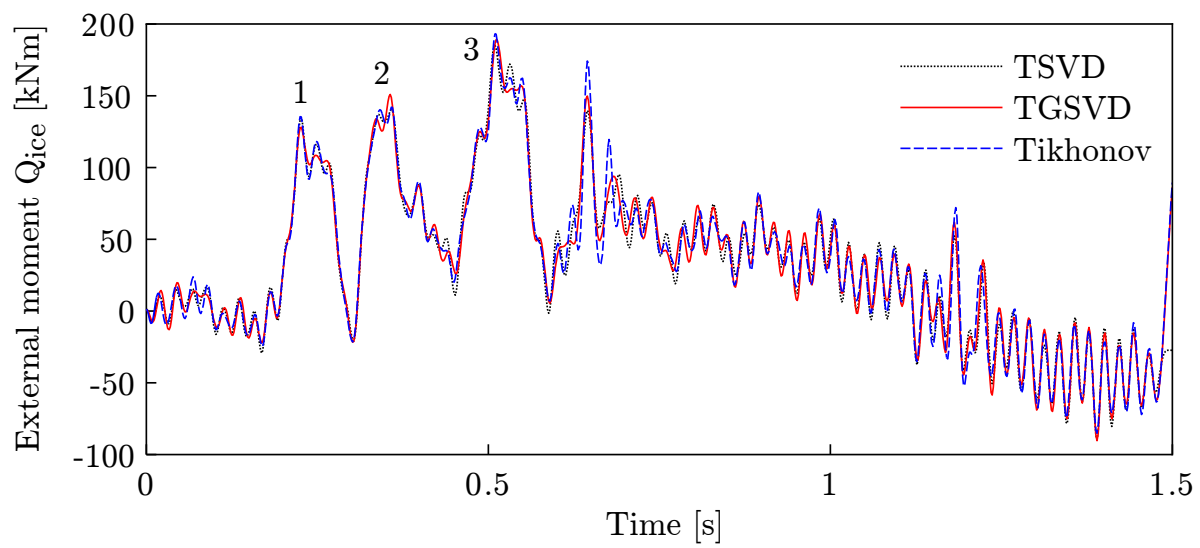

(a) Case 1

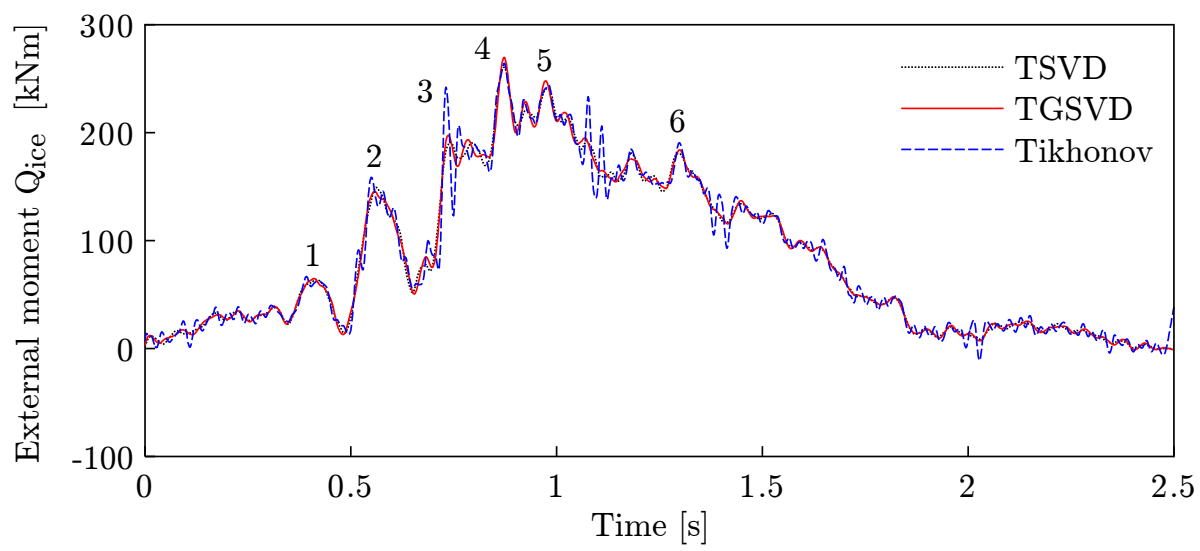

(b) Case 2

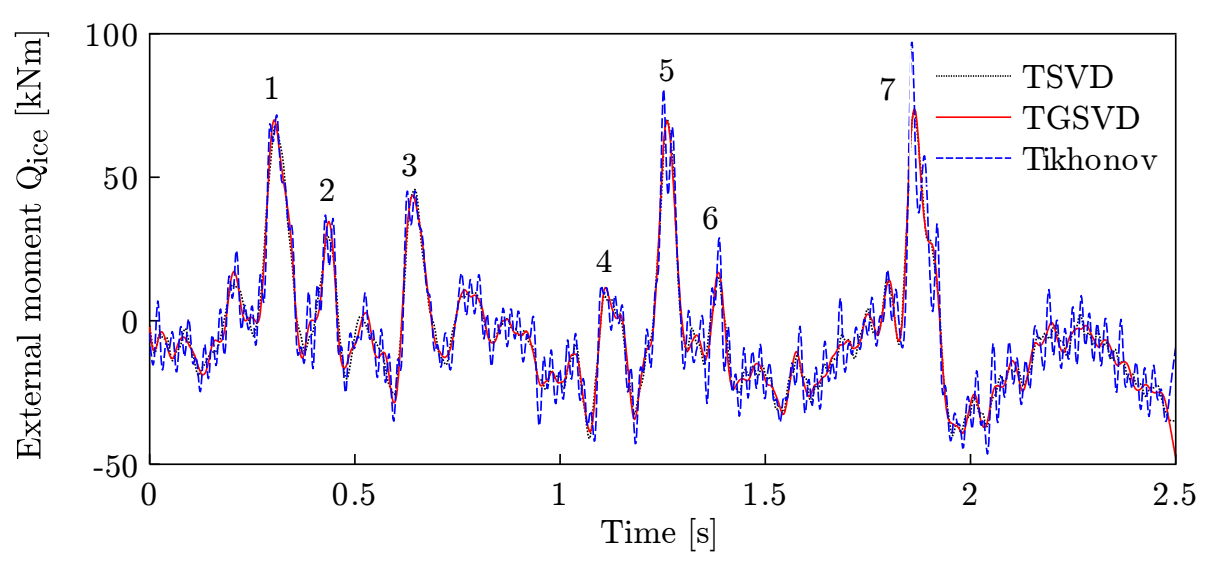

(c) Case 3

Figure 11: External propeller moment determined through inverse methods TSVD, TGSVD and Tikhonov regularization.

From the determined ice-induced moments in Figure 11, the number of ice impacts are more easily observed compared to the measured shaft internal torque in Figure 10. This is partly due to the dynamic response of the shaft line not being included in the external loads. For the first case, three ice impacts are clearly evident (numbered 1 to 3 ) followed by two smaller impacts. For the second case, individual ice impacts were not as prominent as the effect of milling causes multiple impacts to occur shortly after one another. A total of six 
impacts were confidently determined for this case (numbered 1 to 6). In Case 3 there were seven prominent ice impacts (numbered 1 to 7). The duration of ice impacts for these three cases ranged from 25 to 228 milliseconds, where the duration was based on the minimum turning point before and after the first peak caused by the ice impact. From blade measurements performed by Jussila and Koskinen [39] on a car ferry in the archipelago of Åland, ice impact durations of around 40 milliseconds were recorded, thus similar to the durations determined for the current cases.

When analysing the maximum amplitudes for external ice-induced moments $\left(\bar{Q}_{i c e}\right)$ and measured internal torque $\left(Q_{\text {shaft }}\right)$ for these cases, the external moments were consistently found to have greater peak values. This is due to the water damping and dynamic model of the shaft line. For Case $1, Q_{i c e}$ was found to be 64.2\% greater compared to the relative measured $Q_{\text {shaft }}$. However for Cases 2 and 3, this increase was found to be $231.0 \%$ and $206.6 \%$.

\subsubsection{Maximum conditions - Cases 4 and 5}

Case 4 presents the maximum recorded ice-induced torque during the 2015/2016 voyage. The time histories of the internal shaft torque and calculated ice-induced moments are shown in Figure 12 with operational parameters in Table 4 . The ice-induced torque was obtained by subtracting the hydrodynamic load, $\bar{Q}_{h}$ from the measured signal. The operating conditions for this case as well as the absolute maximum value, including the hydrodynamic load, is recorded in Table 5. The selected maximum conditions refer to the maximum recorded shaft line torque for the voyage and do not necessarily translate to the maximum ice-induced torque on the propeller. 


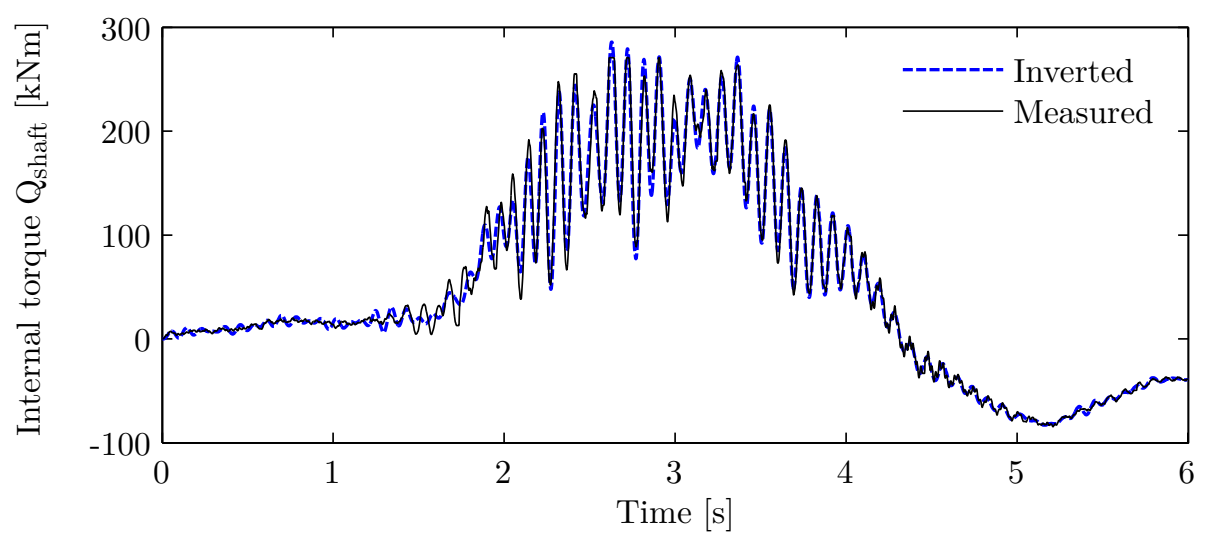

(a) Case 4 - Internal torque

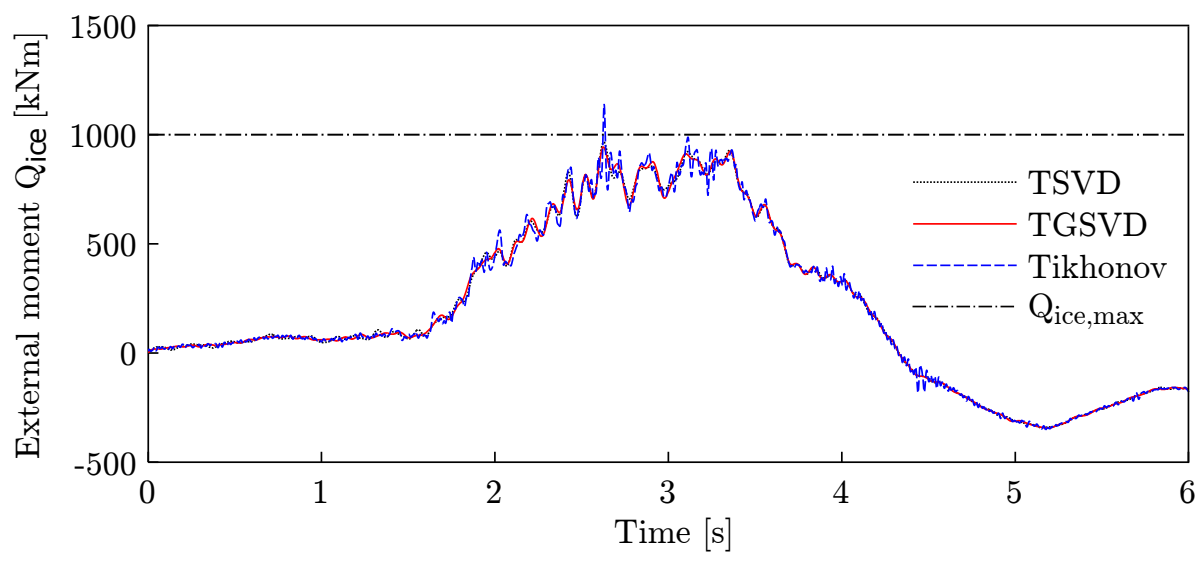

(b) Case 4 - Ice-induced torque

Figure 12: External propeller moment determined from measured shaft line internal torque on the SAA II through inverse methods TSVD, TGSVD and Tikhonov regularization.

The maximum ice-induced external torque was determined through inverse methods from the measured internal torque and presented in Figure 12b. Milling was evident for this case from the multiple ice impacts occurring shortly after one another. From the external ice-induced torque, six significant peaks are evident during the ice impact phase between time $2 \mathrm{~s}$ and $3 \mathrm{~s}$. The impact frequency is close to the blade frequency of $5.67 \mathrm{~Hz}$ for the shaft line speed of $85.1 \mathrm{rpm}$ and denotes milling through consecutive ice impacts of each blade. When analysing the measured internal torque, eleven peaks are evident between time $2 \mathrm{~s}$ and $3 \mathrm{~s}$, which correlates to the first natural frequency of the shaft line. The maximum allowed ice-induced torque on the propeller was determined through the Ice Class Rules, from Equation 18 in the Appendix, to be $1009.9 \mathrm{kNm}$. For TSVD and TGSVD, $\bar{Q}_{i c e}$ did not exceed this limit, however when using Tikhonov regularization this limit was exceeded by $12.6 \%$. 


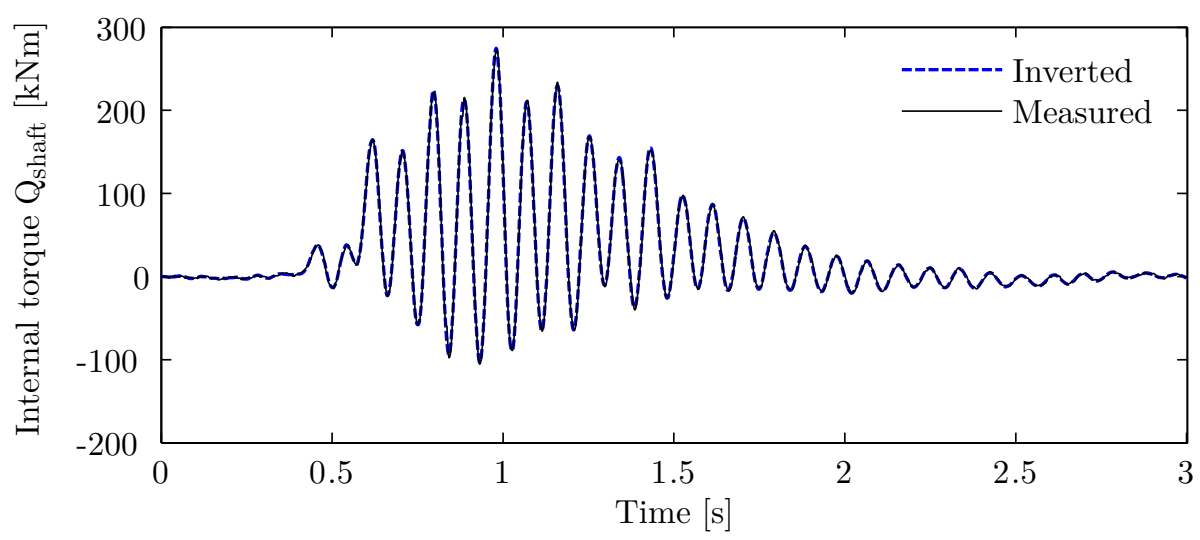

(a) Case 5 - Internal torque

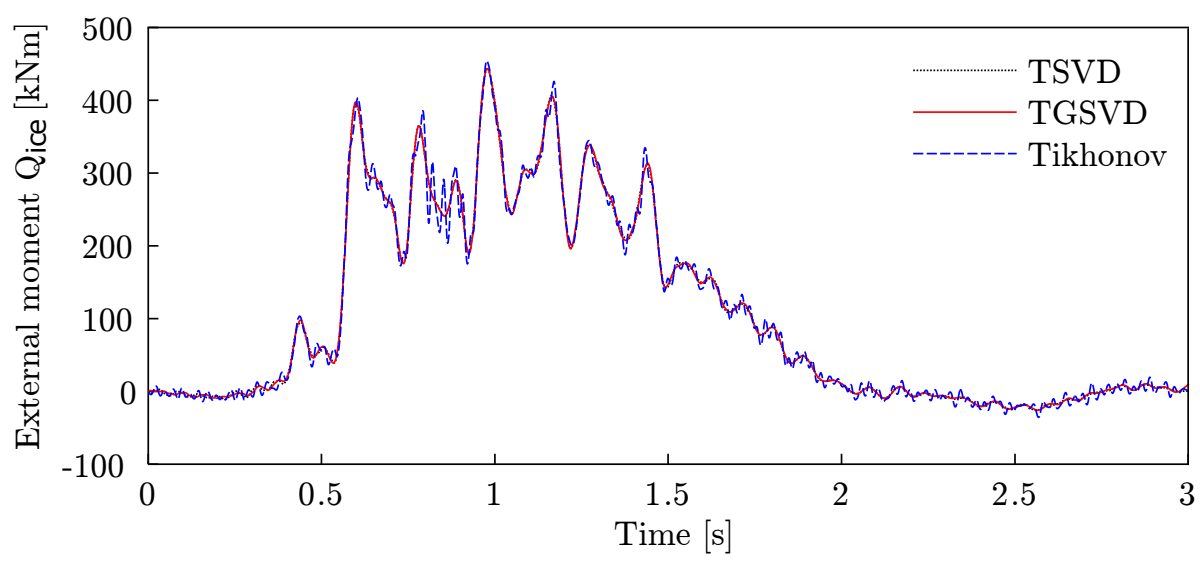

(b) Case 5 - Ice-induced torque

Figure 13: External propeller moment determined from measured shaft line internal torque on the SAA II through inverse methods TSVD, TGSVD and Tikhonov regularization.

Table 5: Operating conditions during maximum recorded ice-induced torque loading.

\begin{tabular}{lccc|c} 
Case & $\begin{array}{c}\text { Maximum } \\
\text { shaft torque } \\
{[\mathrm{kNm}]}\end{array}$ & $\begin{array}{c}\text { Minimum } \\
\text { shaft torque } \\
{[\mathrm{kNm}]}\end{array}$ & $\begin{array}{c}\text { Absolute } \\
\text { maximum } \\
{[\mathrm{kNm}]}\end{array}$ & $\begin{array}{c}\text { Maximum } \\
\text { ice moment } \\
{[\mathrm{kNm}]}\end{array}$ \\
\hline Case 1 & 117.8 & -63.7 & 337.0 & 189.0 \\
Case 2 & 79.8 & -6.3 & 224.7 & 269.6 \\
Case 3 & 31.6 & -27.4 & 342.4 & 73.7 \\
Case 4 & 270.7 & -84.7 & 492.9 & 942.1 \\
Case 5 & 272.9 & -105.6 & 475.3 & 443.4 \\
\hline
\end{tabular}

A second ice loading case (Case 5) containing large torque oscillations was selected for analysis (Figure 13b). It is noted from the ice observations that the vessel impacted a large floe field and that the floes noticeably slowed the ship down at this point. The maximum measured internal torque for this case was $475.3 \mathrm{kNm}$ and the hydrodynamic load $254.3 \mathrm{kNm}$. Similar effects are visible for Case 5 compared to Case 4 , in which the same ice impact frequency is observed for the external ice-induced torque $(6.5 \mathrm{~Hz})$, which has a strong correlation to the blade pass frequency of $6.96 \mathrm{~Hz}$. From the measured internal torque, a frequency of $11 \mathrm{~Hz}$ 
is evident, denoting an excitation of the first natural frequency of the shaft line.

\section{Discussion}

In the consideration of operational ice impact case studies it was found that the judgement on whether the maximum allowed ice-induced torque on the propeller was exceeded or not does depend on the selected regularization method. For TSVD and TGSVD, $\bar{Q}_{i c e}$ did not exceed this limit, however when using the Tikhonov regularization method this limit was exceeded by $12.6 \%$. The evaluation of regularization methods against simulated ice impacts showed that TGSVD resulted in the recovery of peak responses with greater accuracy than TSVD and Thikonov regularization. Although TGSVD better represented the peak values, Tikhonov regularization provided a better general fit of the transient response that follows the ice impact. Therefore it is recommended that TGSVD should be used for peak value estimation, resulting in the maximum external ice-induced moment occurring at $941.5 \mathrm{kNm}$, which is $6.8 \%$ below the maximum allowed ice-induced torque on the propeller.

It was found that the internal torque for ice infested waters resulted in oscillatory torque responses, with the inversely determined external propeller-ice loads being characterized by greater peaks overall. The results obtained were physically reasonable, indicating that the current methods are suitable for obtaining ice-induced loading on the propeller from shaft line measurements. From the studied cases, it was found that ice milling conditions resulted in the greatest measured internal torque and determined ice-induced moment on the propeller. Of the three regularization methods used for inverse force estimation, TGSVD was found to represent impulse moments the best with a maximum error of $-5.4 \%$. Tikhonov regularization matched the reference moment the best overall with a maximum error of $-8.5 \%$ during the linear impulse moment.

\section{Conclusions}

Results from full-scale measurements on-board the SAA II were analysed and discussed. Ice impacts resulted in elevated shaft torque levels, with a maximum torque of $493 \mathrm{kNm}$. Inverse calculations were validated using three regularization methods, namely TSVD, TGSVD and Tikhonov, which allowed for the ill-posed problem to be overcome. The optimum levels of regularization were determined and it is was found that TGSVD better predicts peak responses whereas the Tikhonov method provided a better general fit of the transient response that follows ice impacts. The maximum ice-induced external moment for the investigated case studies was found to be $941.5 \mathrm{kNm}$ through the TGSVD, which was $6.8 \%$ less than the 
maximum allowed ice-induced torque on the propeller. The duration of these ice impacts ranged from 25 to 228 milliseconds. A secondary peak was evident during propeller-ice impacts which is thought to be the back-and-forth propagation of a shear stress wave along the shaft line. From the inversely determined ice-induced loads, the number of impacts, the duration, the shape and the damping of water on the propeller were identifiable.

For future work, it is recommended to design a numerical model with increased precision. This would involve parameter optimization to enable closer matching of natural frequencies. Furthermore, additional measurements on the shaft-line would create greater confidence in the model. Significant future value can be derived from the concurrent analysis and trending of ice-propeller impacts and operational ship parameters such as propeller pitch, ship speed and associated vessel maneuvers which would assist vessel operators to navigate in icy waters with greater safety and efficiency.

\section{Acknowledgements}

The financial assistance of the National Research Foundation (NRF) towards this research is hereby acknowledged. Captain Gavin and the SMIT Amandla crew are acknowledged for their assistance and help in obtaining data during the 2015/2016 voyage to Antarctica. Aalto University, University of Oulu, Finnish Meteorological Institute, Rolls Royce, Wärtsilä, Aker Arctic, STX Finland, DNV, University of Pretoria and the Department of Environmental Affairs of South Africa are acknowledged for their contribution towards this field of research. 


\section{Appendices}

\section{Dynamic model variables}

Table 6: Mass moment of inertia, torsional stiffness and damping constants used for the dynamic model [30].

\begin{tabular}{ll|c} 
Variable & Description & Value \\
\hline$J_{1}$ & Propeller & $1.347 \times 10^{4} \mathrm{~kg} \cdot \mathrm{m}^{2}$ \\
$J_{3}$ & Mid propeller shaft & $5.590 \times 10^{2} \mathrm{~kg} \cdot \mathrm{m}^{2}$ \\
$J_{5}$ & Sleeve coupling & $5.120 \times 10^{2} \mathrm{~kg} \cdot \mathrm{m}^{2}$ \\
$J_{7}$ & OD box flange & $4.870 \times 10^{2} \mathrm{~kg} \cdot \mathrm{m}^{2}$ \\
$J_{9}$ & Thrust shaft collar & $1.410 \times 10^{2} \mathrm{~kg} \cdot \mathrm{m}^{2}$ \\
$J_{11}$ & Motor flange & $1.740 \times 10^{2} \mathrm{~kg} \cdot \mathrm{m}^{2}$ \\
$J_{13}$ & Propulsion motor & $4.415 \times 10^{3} \mathrm{~kg} \cdot \mathrm{m}^{2}$ \\
$c_{1}$ & Water damping & $1.136 \times 10^{5} \mathrm{Nm} \cdot \mathrm{s} / \mathrm{rad}$ \\
$c_{2,4, \ldots, 12}$ & Steel shaft & $-180 \mathrm{Nm} \cdot \mathrm{s} / \mathrm{rad}$ \\
$k_{2}$ & Steel shaft & $5.950 \times 10^{7} \mathrm{Nm} \cdot \mathrm{rad}$ \\
$k_{4}$ & Steel shaft & $5.950 \times 10^{7} \mathrm{Nm} \cdot \mathrm{rad}$ \\
$k_{6}$ & Steel shaft & $1.120 \times 10^{8} \mathrm{Nm} \cdot \mathrm{rad}$ \\
$k_{8}$ & Steel shaft & $6.930 \times 10^{8} \mathrm{Nm} \cdot \mathrm{rad}$ \\
$k_{10}$ & Steel shaft & $5.090 \times 10^{8} \mathrm{Nm} \cdot \mathrm{rad}$ \\
$k_{12}$ & Steel shaft & $1.430 \times 10^{8} \mathrm{Nm} \cdot \mathrm{rad}$ \\
\hline
\end{tabular}

\section{DNV Ice Class Rules}

The DNV Ice Class Rules define the requirements for varying types of vessels, which are occasionally or primarily intended for navigation in ice. According to the DNV Rules, the maximum torque on a propeller due to ice influence, for a PC-5 rated vessel, can be defined as follows [7]:

For $D<D_{\text {limit }}$

$$
Q_{i c e, \max }=N_{1}\left(1-\frac{d_{h}}{D}\right)\left(\frac{P_{0.7}}{D}\right)^{0.16}(n D)^{0.17} D^{3}
$$

For $D \geq D_{\text {limit }}$

$$
Q_{i c e, \max }=N_{2}\left(1-\frac{d_{h}}{D}\right)\left(H_{i c e}\right)^{1.1}\left(\frac{P_{0.7}}{D}\right)^{0.16}(n D)^{0.17} D^{1.9}
$$

with

$$
D_{\text {limit }}=1.8 H_{\text {ice }}
$$

where $N_{1}$ and $N_{2}$ are equal to 14.7 and 27.93 for open propellers and 10.4 and 19.76 for ducted propellers. [7] describes three cases containing a sequence of blade impacts, which are modelled as half sinusoidal functions. This loading profile is used to model the propeller-ice torque excitation for shaft line dynamics. The torsional excitation is described according to varying conditions as presented in Table 7, with Figure 14 
displaying the torque excitation time histories.

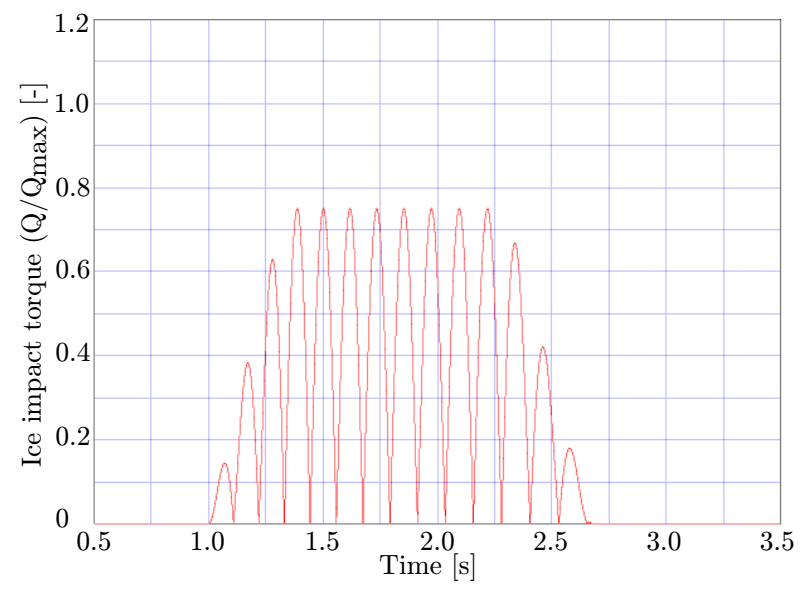

(a) Case 1

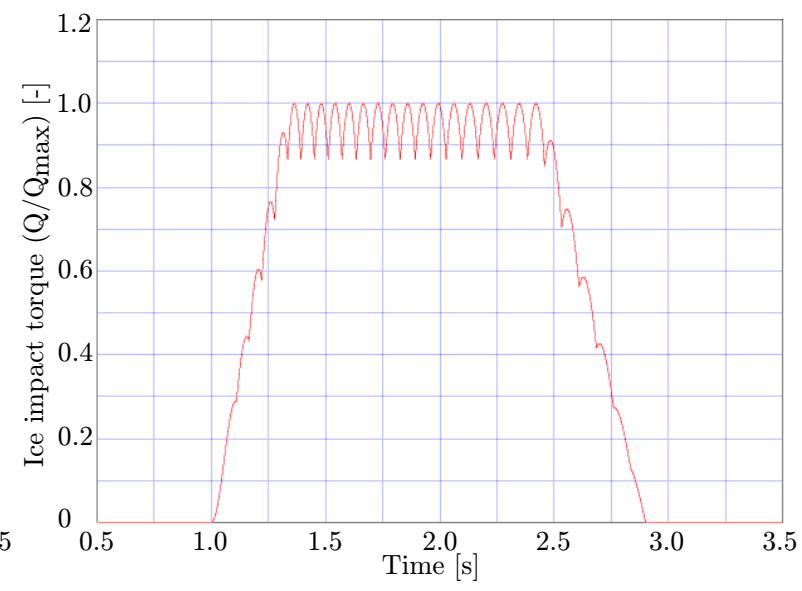

(b) Case 2

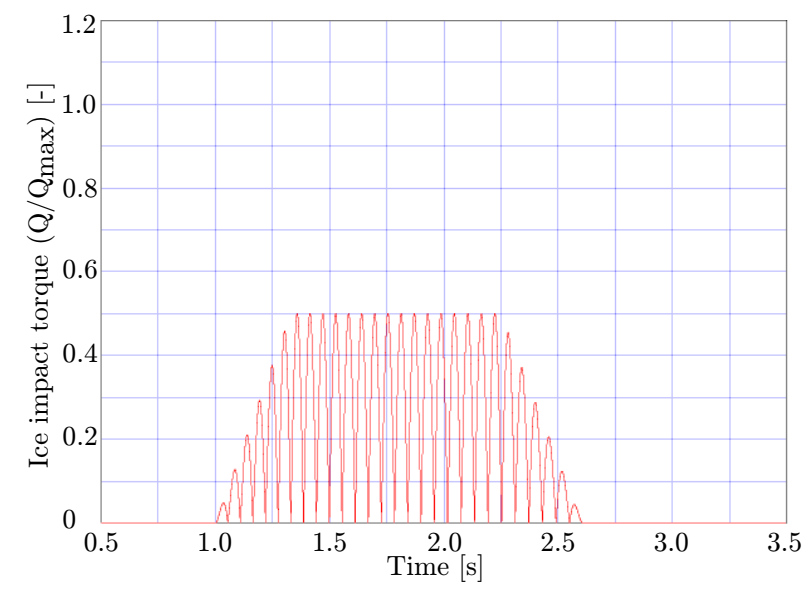

(c) Case 3

Figure 14: Modelled torque excitation on the propeller used for shaft line dynamic analysis. These propellerice interactions are for four bladed propellers during (a) $90^{\circ}$ and (b) $135^{\circ}$ single-blade impact sequence and (c) $45^{\circ}$ double bladed impact sequence. Adapted from [7].

A single blade impact can be described by a half-sine impact function, which is expressed in terms of the propeller rotation angle using the $C_{q}$ and $\alpha_{i}$ parameters with the maximum ice-induced torque on the propeller:

For $\varphi=\left[0, \alpha_{i}\right]$

$$
Q_{i c e}(\varphi)=C_{q} Q_{i c e, \max } \sin \left(\varphi \frac{180}{\alpha_{i}}\right)
$$

For $\varphi=\left[\alpha_{i}, 360^{\circ}\right]$

$$
Q_{\text {ice }}(\varphi)=0
$$

$\alpha_{i}$ is expressed in terms of the propeller rotation angle (degrees) versus the duration of propeller-ice interaction and $C_{q}$ is defined as an empirical coefficient defining the magnitude of these impacts. Transient 
torsional vibration analysis should be used to determine the response torque $Q_{\text {shaft }}$ at any component in the propulsion system through the excitation torque $Q_{i c e}$ applied at the propeller [7]. The excitation torque $Q_{i c e}$ needs to be superimposed on the bollard condition hydrodynamic torque when performing calculations for all three cases.

Table 7: Torque excitation parameters for different ice cases [7].

\begin{tabular}{llcc} 
Torque excitation & Ice-propeller interaction & $C_{q}$ & $\alpha_{i}$ \\
\hline Case 1 & Single ice block & 0.75 & $90^{\circ}$ \\
Case 2 & Single ice block & 1 & $135^{\circ}$ \\
Case 3 & Two ice blocks & 0.5 & $45^{\circ}$ \\
\hline
\end{tabular}

\section{References}

[1] T. Ikonen, O. Peltokorpi, and J. Karhunen, "Inverse ice-induced moment determination on the propeller of an ice-going vessel," Cold Regions Science and Technology, vol. 112, pp. 1-13, 2014.

[2] I. Ansorge, P. Skelton, A. Bekker, P. Nico De Bruyn, D. Butterworth, P. Cilliers, J. Cooper, D. Cowan, R. Dorrington, S. Fawcett, S. Fietz, K. Findlay, P. Froneman, G. Grantham, M. Greve, D. Hedding, G. Greg Hofmeyr, M. Kosch, P. Le Roux, M. Lucas, K. MacHutchon, I. Meiklejohn, W. Nel, P. Pistorius, P. Ryan, J. Stander, S. Swart, A. Treasure, M. Vichi, and B. Van Vuuren, "Exploring South Africa's southern frontier: A 20-year vision for polar research through the South African national antarctic programme," South African Journal of Science, vol. 113, no. 5-6, pp. 1-7, 2017.

[3] R. D. Barro and D. C. Lee, "Excitation response estimation of polar class vessel propulsion shafting system," Transactions of the Korean Society for Noise and Vibration Engineering, vol. 21, no. 12, pp. 1166-1176, 2011.

[4] International Association of Classification Societies, "Requirements concerning polar class," 2016.

[5] Korean Register, "Guidance for ship for navigation in ice," 2015.

[6] American Bureau of Shipping, "Guidance notes on ship vibration,” 2006.

[7] Det Norske Veritas, "Classification of ships for navigation in ice," Rules for Classification of Ships, vol. 5, no. 1322, 2011.

[8] Germanischer Lloyd, "Rules for classification and construction," Part 6 Offshore Technology, Chapter 5 Machinery Installations, Section 7 Torsional Vibrations, 2007. 
[9] Finnish Maritime Administration and Swedish Maritime Administration, "Guidelines for the application of the Finnish - Swedish Ice Class Rules,” vol. 1, 2005.

[10] Y. A. Batrak, A. M. Serdjuchenko, and A. I. Tarasenko, "Calculation of torsional vibration responses in propulsion shafting system caused by ice impacts," in Torsional Vibration Symposium, no. May 21-23, (Salzburg), 2014.

[11] R. J. O. De Waal, A. Bekker, and P. S. Heyns, "Bi-Polar Full-Scale Measurements of Operational Loading on Polar Vessel Shaft-Lines," in Port and Ocean Engineering under Arctic Conditions, (Busan, Korea), 2017.

[12] D. Polić, S. Ehlers, V. Æsøy, and E. Pedersen, "Shaft response as a propulsion machinery design load," in Proceedings of the ASME 2014 33rd International Conference on Ocean, Offshore and Arctic Engineering OMAE2014, (California,), 2014.

[13] S. Hänninen, "Incidents and accidnets in winter navigation in the Baltic Sea, Winter 2002-2003," tech. rep., Finnish Winter Navigation Research Board, 2004.

[14] K. Riska, “Design of Ice Breaking Ships,” tech. rep., 2011.

[15] L. Norhamo, G. M. Bakken, O. Deinboll, and J. J. Iseskar, "Challenges related to propulsor â ice interaction in arctic waters," in First International Symposium on Marine Propulsors, no. June, (Trondheim, Norway), 2009.

[16] B. Al-Bedoor, S. Aedwesi, and Y. Al-Nassar, "Blades condition monitoring using shaft torsional vibration signals," Journal of Quality in Maintenance Engineering, vol. 12, no. 3, pp. 275-293, 2006.

[17] Q. He and D. Du, "Modeling and calculation analysis of torsional vibration for turbine generator shafts," Journal of Information and Computational Science 7, vol. 10, pp. 2174-2182, 2010.

[18] G. H. Golub, P. C. Hansen, and D. P. O’Leary, “Tikhonov regularization and total least squares," Siam Journal on Matrix Analysis and Applications, vol. 21, no. 1, pp. 185-194, 1999.

[19] E. Jacquelin, A. Bennani, and P. Hamelin, "Force reconstruction: Analysis and regularization of a deconvolution problem," Journal of Sound and Vibration, vol. 265, no. 1, pp. 81-107, 2003.

[20] M. Suominen, J. Karhunen, A. Bekker, P. Kujala, M. Elo, R. Von Bock Und Polach, H. Enlund, and S. Saarinen, "Full-scale measurements on board PSRV S.A. Agulhas II in the Baltic Sea," in Proceed- 
ings of the International Conference on Port and Ocean Engineering under Arctic Conditions, POAC, 2013.

[21] A. Bekker, M. Suominen, O. Peltokorpi, J. Kulovesi, P. Kujala, and J. Karhunen, "Full-scale measurements on a polar supply and research vessel during maneuver tests in an ice field in the Baltic Sea," in Proceedings of the International Conference on Offshore Mechanics and Arctic Engineering - OMAE, vol. 10, 2014.

[22] M. R. Myklebost and G. Dahler, "Agulhas II data analysis of torsional shaft responses from operation in Arctic waters - Technical summary report,” tech. rep., Det Norske Veritas, 2013.

[23] R. J. O. De Waal, "An investigation of shaft line torsional vibration during ice impacts on PSRVs," Master's thesis, Stellenbosch University, 2017.

[24] STX Finland Oy, "Polar supply and research vessel shaft line arrangement," 2012.

[25] P. Kujala, J. Kulovesi, J. Lehtiranta, and M. Suominen, "Full-scale measurements on board S.A. Agulhas II in the Antarctic waters 2013-2014,” tech. rep., Aalto University, 2014.

[26] K. Hoffmann, "Applying the wheatstone bridge circuit," HBM W1569-1.0 en, HBM, Darmstadt, Germany, pp. 1-28, 2001.

[27] Rolls-Royce AB, "Whirling calculation," Report SA1090, pp. 1-15, 2010.

[28] Escher Wyss, “Gesamtanordnung VP Anlage,” 1980.

[29] Metallurgica Veneta, "Material specifications for S355J2," 2004.

[30] Rolls-Royce AB, "Ice impact simulation - polar research vessel," RRAB STX Research Vessel RES 05B40400 20100414, vol. 110, pp. 1-9, 2010.

[31] E. L. Wilson, Three-dimensional static and dynamic analysis of structures - A physical approach with emphasis on earthquake engineering, vol. 90. California, USA: Computers and Structures Inc., third ed., 2002.

[32] R. V. Dukkipati, MatLab - An introduction with applications. New Delhi: New Age International Publishers, 2010.

[33] D. Inman, Engineering vibration. USA: Pearson Education, 4th ed., 2014. 
[34] P. C. Hansen, Computational inverse problems in electrocardiology, vol. 5. Southampton: WIT Press, 2001 .

[35] C. Hansen, "A Matlab Package for Analysis and Solution of Discrete Ill-Posed Problems.” 2008.

[36] L. Dykes and L. Reichel, "Simplified GSVD computations for the solution of linear discrete ill-posed problems," Journal of Computational and Applied Mathematics, vol. 255, pp. 15-27, 2014.

[37] P. C. Hansen, "Regularization tools version 3.0 for Matlab 5.2,” vol. 6, pp. 1-35, 1994.

[38] R. G. Budynas and J. K. Nisbett, Shigley's mechanical engineering design. New York: McGraw-Hill, 9th ed., 2011.

[39] M. Jussila and P. Koskinen, "Ice loads on propeller blade of small car ferry," in The 10th International Conference on Port and Ocean Engineering under Arctic Conditions (POAC), vol. 2, (Luleå, Sweden), pp. 862-872, 1989. 